precipitate gastric emptying and then occurs soon after meals. A degree of steatorrhoea is common after gastrectomy.

\section{Asthenia}

The least understood of all the sequelae of gastrectomy is asthenia and often this is a patient's only complaint. Herein lies an important and almost virgin field for research. Testosterone will relieve this symptom to some extent in males.

\section{In Conclusion}

It must be borne in mind that not all postprandial symptoms complained of by patients who have had gastrectomies are sequelae to their operations or recurrences of their peptic ulcers. Pain shortly after food should always suggest a lesion of the large bowel, or gall bladder disease may have supervened. Anorexia, weight loss and vomiting can mean a carcinoma in the gastric remnant or the patient may have chronic retention and be passing into uraemia.

The pain due to stomal ulcer after Polya gastrectomy can be very like that which sometimes accompanies dumping, for both tend to come on sooner after food than did the pain of the former duodenal ulcer, both may be eased by sodium bicarbonate and either may be unrelieved by food. If sweetened milk causes pain, dumping is probably the cause, and if alcohol brings on the distress recurrent ulcer is more likely.

A few patients are never relieved of their ulcerlike symptoms by their gastrectomies. Very rarely indeed this is due to the immediate development of a stomal ulcer. The writer was asked by a colleague to see a patient who had had a severe haemorrhage ro days after gastrectomy, in whom such an early recurrence was found to be the cause.
Some of the remaining patients have developed dumping symptoms which they have been unable to distinguish from their former ulcer ones. The rest mostly had other lesions, as well as their ulcers, all along, lesions which were not detected and remained untreated. Far the commonest of these is reflux peptic oesophagitis, for this quite often co-exists with duodenal or with gastric ulcers. The writer has operated upon three such patients, found to have hiatal herniae, who had been referred to him because their ulcer-like symptoms had persisted after gastric resection. Both hiatus hernia and oesophageal reflux can escape detection even at the most careful X-ray examination and only by oesophagoscopy can oesophagitis be diagnosed or excluded with assurance.

Frequent and persistent bilious regurgitation, such as may occur after total or near total gastrectomy, can produce a troublesome oesophagitis as one of its complications, an oesophagitis which is presumably triptic in origin.

\section{BIBLIOGRAPHY}

BUTLER, T. J., and CAPPER, W. M. (195I), Brit. med. F., i, 1177. GLAZEBROOK, A. J. (1952), Ibid., ii, 598.

GOLLIGHER, J. C., and RILEY, T. R. (I95?), Lancet, i, 630.

HENLEY, F. A. (1953), Ann. royal Coll. Surg., 13, 141.

JOHNSON, H. D. (1948), Proc. royal Soc. Med., 41, 649.

JOHNSON, H. D. (1950), 'Techniques in British Surgery,' Saunders, New York.

JOHNSON, H. D., and ORR, I. M. (1953), Lancet, i, 253.

MACHELLA, I. E. (1949), Surg., 130.

MORONEY, J. (1953), Ann. royal Coll. Surg., 12, 328.

O'NEIL, T. (1950), Brit. med. F., il, 15.

PERMAN, E. (1947), Acta. med. scand., Suppl. 196, 316.

RAY, B. S., and NEILL, C. (1947), Ann. Surg., 126, 709.

SCHOFIELD, J. E. (1953), Brit. med. $\mathcal{F}$., ii, 598.

SMITH, W. H., FRASER, R., STAYNES, K., and WILLCOX, J. M. (1953), Quart. med. F., xxil, 381 .

STAPLER, N. M. (1949), Gastroenterol., 13, 34r.

STEINBERG, M. E. (1949), Surg. Gynec. Obstet., 88, 453.

WELBOURN, R. B.; and GLAZEBROOK, A. J. (r952), Brit. $\mathcal{f}$. Surg., 40, 111 .

WELLS, C. A., WELBOURN, R. B. (r951), Brit. med. f., i, 546.

\title{
PULMONARY TUBERCULOSIS FOLLOWING PARTIAL GASTRECTOMY
}

\author{
By R. S. Bruce Pearson, D.M., F.R.C.P.
}

It is still uncertain whether partial gastrectomy predisposes to the development of pulmonary tuberculosis. Reference to this possibility is made in papers by Pulvertaft, Drablos, Swynnerton and Tanner and Warthin. Isorni observed 21 gastrectomized cases among 742 patients in a French sanatorium and thought that the association was too frequent to be coincidental. In this paper II cases of active pulmonary tuberculosis following partial gastrectomy are recorded. Four were seen in the course of a five-year follow-up of 93 partial gastrectomies. Five were inmates of a ward for chronic pulmonary tuberculosis and two others were encountered in the course of routine hospital work.

Two additional cases were also seen in the 


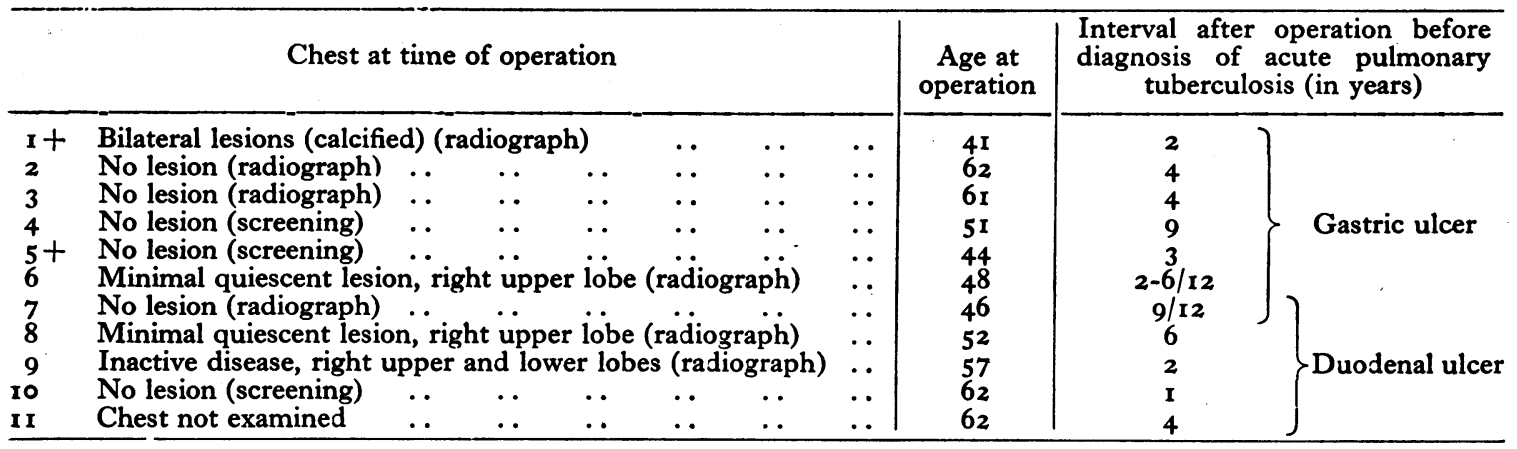

immediate post-operative period-one was known to have an apparently quiescent lesion and the second can be presumed to have had one at the time of operation. Although there is little doubt that quiescent chest disease was activated in these two patients by the combined effect of abdominal surgery and anaesthesia, there is no reason to suspect that the exact nature of the operation was important. These patients resemble those described by Olmer and Huguet in the short interval between surgery and the diagnosis of active tuberculosis. They will not be further discussed.

The I I patients under review were all over 40 years of age; ro were men and one a woman.

\section{Condition of the Lungs}

In five patients the lungs were reported clear at the time of operation, but in two of these screening only appears to have been carried out. In two other cases (Nos. 6 and 8) the radiograph was reported to be normal at the time of the operation and in one of these at mass X-ray five years later, but examination of the original films showed a minimal lesion in both at the right apex where active disease was subsequently discovered. In two other cases $(1,9)$, one of whom had undergone sanatorium treatment some years previously, quiescent lesions were known to have been present. In two there was no information as to the condition of the chest, but there was nothing in the history to suggest that a lesion had been present.

These findings and the interval that elapsed between the time of operation and the diagnosis of active tuberculosis are shown in Table. I. It will be seen that in nine there was an interval of two years or more. Both lungs were affected in eight cases, one in two, and in one no details are available. This patient (No. 5) and one other (No. I) died of tuberculosis.

\section{Type of Operation}

A Polya type of anastomosis was carried out in all the cases. In eight the anastomosis was ante- colic, in one retrocolic and in one the operative details are unknown. Cases recorded by Swynnerton and Tanner had also antecolic anastomoses, but in Drablos's series retrocolic anastomoses were usual.

Of the seven cases with gastric ulcer, it was reported at the time of operation that the ulcer was 'very large and adherent ' in four, two ulcers were present in one, and in one a duodenal ulcer was present as well as a gastric ulcer. The area of stomach removed in these cases varied between $2 / 3$ to $5 / 6$. In one patient with a duodenal ulcer a 5/6 removal was carried out. The availableo evidence therefore suggests that an extensive resection was undertaken in most cases.

\section{Post-operative Progress}

Four cases $(2,3,7,8)$ had severe postgastrectomy symptoms with bilious vomiting, abdominal distension and faintness occurring shortly after food; they ate small meals usually at long intervals. These men were all under weight at the time of operation. One maintained his pre-operative weight, but the other three continued to lose. Two others (4, 10), though they did not complain of symptoms, stated that they could only take small meals without discomfort and both lost weight following gastrectomy. In each of these six cases the tuberculous infection was the culminating point of a long period of under-nutrition which was maintained in spite of almost constant medical supervision. Five patients $(\mathrm{r}, 5,6,9, \mathrm{I})$ regarded the operation as completely successful with at most minor symptoms. One of these (6) complained of severe abdominal pain two years after operation and from this time he became afraid to eat and lost weight rapidly until a diagnosis of pulmonary tuberculosis was made two and a half years after operation (see Table 2). Three of these five ' successful' cases had known quiescent chest lesions at the time of operation.

Secondary factors sometimes played a part in further increasing their ill health. Thus one had 


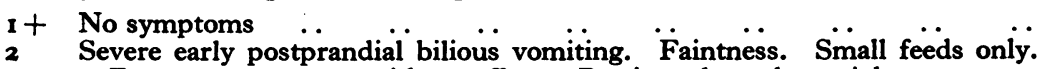
Entero-enterostomy without effect. Persistently under weight .. ...

3 Vomiting of bile. Small feeds only. Persistently under weight. Depression

4 Small feeds only. Persistently under weight

$5+$ Occasional biliary regurtitation $\quad \ldots \quad \ldots \ldots \ldots$

6 No symptoms for two years, then severe epigastric pain which made him

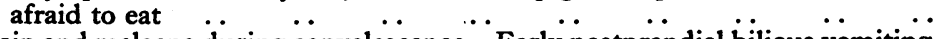

$7 \quad$ Pain and melaena during convalescence. Early postprandial bilious vomiting. Pain. Small feeds only. Adhesions cut after one year without relief.

8 Severe early postprandial bilious vomiting. Faintness. Small feeds only.

$\begin{array}{llllllll}\text { Persistently under weight } & \ldots & \ldots & \ldots & \ldots & \ldots & \ldots & \ldots \\ \text { No symptoms. Appetite poor } & \ldots & \ldots & \ldots & \ldots & \ldots & \ldots & \ldots\end{array}$ Small meals only. Persistently under weight
Unable to take milk, otherwise no symptoms. Post-operative increase in

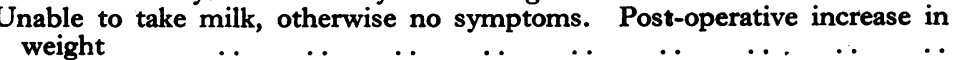

\begin{tabular}{|c|c}
$\begin{array}{c}\text { Maximum } \\
\text { pre-operative } \\
\text { weight }\end{array}$ & $\begin{array}{c}\text { Weight at } \\
\text { onset of } \\
\text { pulmonary } \\
\text { tuberculosis }\end{array}$ \\
\hline Unknown & Unknown \\
$12-2$ & $7-13$ \\
$9-1$ & $6-10$ \\
$10-7$ & $6-8$ \\
Unknown & Unknown \\
$11-4$ & $7-9$ \\
& $10-2$ \\
$12-10$ & $7-6$ \\
$10-0$ & $7-8$ \\
$8-4$ & $7-7$ \\
$11-6$ & \\
$8-0$ &
\end{tabular}

Table 3. Incidence of Pulmonary Tuberculosis Following Partial Gastrectomy

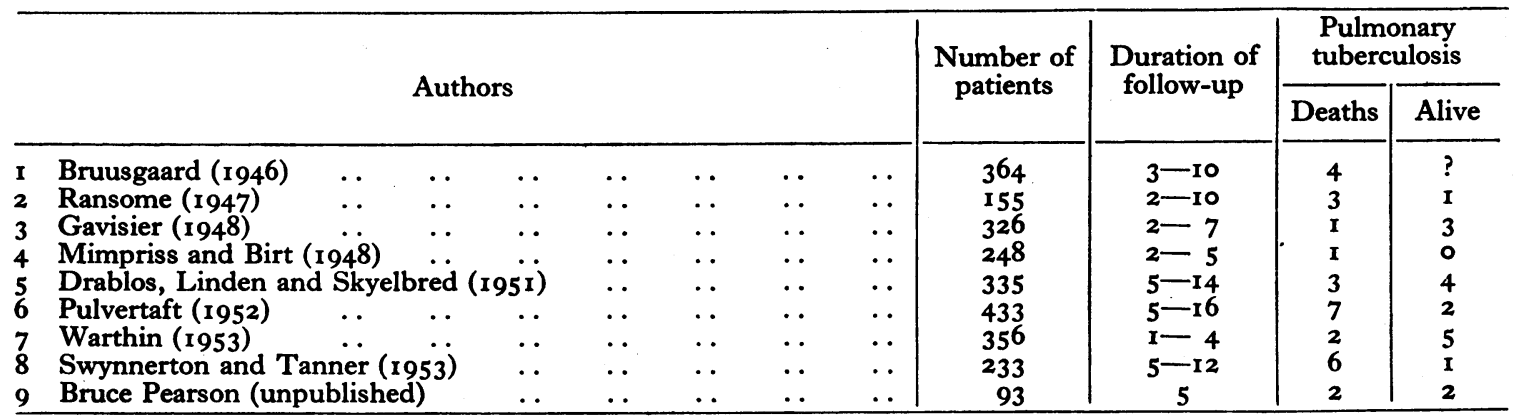

been constantly out of work (I), one had had repeated changes of work (3), and a third could only obtain work as a night watchman (4). The remainder continued to carry out their pre-operative occupations until their chest lesions were diagnosed. In two patients emotional factors were important: one had signs of chronic anxiety with depression (3) and one deteriorated rapidly following the death of his wife (4).

\section{Discussion}

Figures concerning the incidence of pulmonary tuberculosis after gastrectomy are scanty. Table 3 summarizes the cases recorded in published series followed up for a number of years. Most authors have been interested in the surgical sequelae of gastrectomy and give little information relating to apparently incidental lesions: among all these papers only Warthin's was primarily concerned with the possible effect of gastrectomy in predisposing to tuberculosis. Information is particularly scanty concerning the condition of the lungs before operation and the interval between opera- tion and the diagnosis of tuberculosis. In over 2,500 cases recorded in all these publications there are 29 deaths from pulmonary tuberculosis and 18 survivors with active tuberculous disease, giving a total incidence of over 2 per cent. In those series where the minimal period of observation is five years this figure varies between 2 and 4 per cent. The total mortality for all series is I.I per cent.

The significance of such figures can only be appreciated in comparison with those for the general population. Unfortunately, insufficient information is given as to the make-up of many published series in respect of age and sex to enable a satisfactory statistical comparison to be made. Moreover, the duration of the period of follow-up varies from two to 16 years and the observations have been carried out in different parts of the world.

The majority of patients who are subjected to gastrectomy are men over 40 years of age; the recorded cases of tuberculosis after gastrectomy occur in this age group (IO of the I I cases recorded in this paper, five of Pulvertaft's, five of Swynner- 
ton's and seven of Warthin's). It must be remembered that this section of the population has a particularly high death rate from tuberculosis, at least in this country. Thus in $195^{\circ}$ there were 0.99 deaths per 1,000 from this cause in men over 45 years of age in the administrative county of London, whereas among women of the same age there were only 0.22 deaths and for males between I 5 and 44 only 0.34 deaths per 1,000 living. In 1939 the death rate from pulmonary tuberculosis among males over 45 years was $\mathrm{r} .6 \mathrm{I}$ per $\mathrm{I}, 000$ living. Thus in a period of ro years between these dates it might be expected that I.3 per cent. of deaths in men over 45 would be attributable to pulmonary tuberculosis. It would not be fair, however, to compare this figure with that (I.I per cent.) recorded in the series of gastrectomized patients reviewed in Table 3 for a variety of reasons. These series include a number of men under 45 . and a proportion of women, both with a lower mortality rate. The observations have been made in different places and at different periods of time. Moreover, in the population at large many of the deaths from tuberculosis which occur in the older age groups take place in individuals with chronic infection of many years' standing and this class of patient would only be submitted to gastrectomy under exceptional circumstances. A more useful comparison could be made between those cases of peptic ulcer treated medically and those treated surgically.

Since statistical comparison is not at present practicable, one must resort to a study of individual case histories in order to arrive at some conclusion as to the possible effect of gastrectomy in precipitating tuberculosis. In six of the II cases who form the subject of this paper severe weight loss preceded the development of active pulmonary tuberculosis: four of these cases had severe postgastrectomy symptoms. In one other case there was some doubt as to whether weight loss preceded the activation of tuberculosis or not. It is clear that the proportion of patients with postgastrectomy symptoms in this series is very high, compared with the usually accepted figure of 5 per cent. It appears, therefore, that the incidence of pulmonary tuberculosis is likely to be relatively higher in this small group of ' failed ' gastrectomy patients compared with the large majority who are symptom free. Warthin also points out the importance of weight loss in precipitating tuberculous disease. Four of the II cases were known to have had quiescent chest lesions at the time of their operation and, as one would expect, the hazard appears to be particularly great in such patients. From the evidence presented it seems that partial gas- trectomy may predispose to the development of active pulmonary tuberculosis in those cases who remain or become markedly under weight following surgery and in those with recognizable quiescent lesions at the time of operation. It therefore appears reasonable to suggest that all patients should have their chests $\mathrm{X}$-rayed prior to partial gastrectomy; that extensive excision should be avoided when there is a known quiescent chest lesion; and that patients with malnutrition following gastrectomy should be regarded as potential cases of pulmonary tuberculosis, should have their chests examined periodically and should be encouraged to eat concentrated high calorie foods in order to make up for reduction in quantity. Pulmonary tuberculosis will always predominantly affect individuals suffering from malnutrition from whatever cause: it is not surprising that this should sometimes be a sequel to gastrectomy; what is more remarkable is the fact that so many patients deprived of an important organ of digestion should suffer so little disturbance of health.

\section{Summary}

I. Eleven cases of pulmonary tuberculosis following partial gastrectomy are recorded.

2. In six of these there was no obvious infiltrao of tion of the chest at the time of operation. In foun. others a quiescent lesion was known to have beep present and in one information is lacking.

3. Six of these cases suffered from postgastrectomy symptoms, leading to weight loss prior to the development of active pulmonary tuberculosis. It is suggested that long-standing malnutrition has in these cases culminated in a tuberculous infection.

\section{Acknowledgments}

I am grateful to Dr. E. V. Saunders Jacobs for permission to examine the cases under her care and to my surgical colleagues for permission to record their cases.

\section{BIBLIOGRAPHY}

BRUUSGAARD, C. (1946), Acta. Chir. Scand., 94, Suppl. 17. DALEY, SIR A. (1950), ' Report of the County Medical Officer of Health and School Medical Officer,' London County Council. DRABLOS, A., LINDEN, V., and SKYELBRED, P. (195I), Acta. Med. Scand., 140, 327.

GAVISIER, D. (1948), Surg., 24, 873.

ISORNI, FABRE, LE MONIET, BAUSSANT and LANG (1948), Rev. de Tubere., 12, 393.

MIMPRISS, T. W., and BIRT, ST. J. M. C. (1948), Brit. med. F., ii, I095.

OLMER, J., and HUGUET, R. (1947), Pres. Med., 55, 834.

PULVERTAFT, C. N. (1952), Lancet, i, 225.

RANSOME, H. K. (1947), Ann. Surg., 126, 633.

SWYNNERTON, B. F., and TANNER, N. C. (1953), Brit. med. F., 11,841 .

WARTHIN, T. A. (1953), Am. F. Med. Sci., 225, 421. 